\title{
Outgroup Contact, Anti-Foreigner Attitude, and Social Cohesion in the Caucasus: Evidence from a Population-Based Survey
}

\author{
Harris Hyun-soo Kim $\mathbb{D}$ \\ Department of Sociology, College of Social Sciences, Ewha Womans University, 52 Ewhayeodae-gil \\ Seodaemun-gu, Seoul 03760, Korea; harrishkim@ewha.ac.kr
}

Received: 9 April 2019; Accepted: 29 May 2019; Published: 10 June 2019

\begin{abstract}
A substantial literature has emerged examining the relationship between ethnic diversity due to immigration and social cohesion in the host country. Empirical evidence concerning this relationship, however, remains inconsistent, if not contradictory. Aside from rare exceptions, the bulk of evidence is also based on North American and European countries. The present study focuses on a novel empirical context: Georgia, a country located in the South Caucasus. Based on multilevel modeling of population-based data, it examines the associations between outgroup contact and attitude toward immigrants and two measures of social cohesion: generalized trust and civic engagement. Results show that net of controls at individual and regional levels, a negative orientation toward foreigners significantly predicts lower trust in generalized others. Frequency of outgroup contact, on the other hand, is positively related to civic participation. This linkage is also weaker in geographic areas with higher levels of anti-immigrant attitude. A major policy implication from this study is to encourage more intergroup contact through effective residential integration, amongst other measures.
\end{abstract}

Keywords: outgroup contact; anti-foreigner attitude; social cohesion; immigration

\section{Background}

Our contemporary period has been aptly dubbed the "age of migration" (Castells et al. 2014). In the wake of this global reality, there have been massive efforts to analyze, in particular, the consequences of transnational human mobility. Perhaps no other issue has been more contested than the one surrounding immigration and its social impact on the host country. In fact, a voluminous literature has emerged addressing this politically sensitive and charged topic (Van Der Meer and Tolsma 2014; Dinesen and Sonderskov 2018). At the center of debate is whether immigration-induced ethnic diversity and social cohesion (social capital) are incompatible. That is, does the former have a corrosive effect on the latter, as has been shown (Fieldhouse and Cutts 2010; Helbling et al. 2015; Putnam 2007; Ziller et al. 2018)?

This debate was stimulated by the so-called 'hunkering down' thesis originally proposed by Putnam (2007). Based the US data, he argued that ethnic heterogeneity has a negative impact on the social fabric of host countries, at least in the short run, since native members presumably withdraw from civic duties and activities in the context of growing immigrant population. In short, ethnic diversity erodes social capital as people tend to trust less and pull away from social interaction. Over the years, a large volume of work has emerged to empirically validate or refute this controversial claim (Kaufmann and Goodwin 2018). This literature has evolved to emphasize two diametrically opposing views provided by the contact and conflict theories (Laurence and Bentley 2018). According to the former theory, ethnic heterogeneity increases the opportunities for beneficial intergroup contact, 
ultimately creating more positive views and attitudes toward the outgroup members. The latter theory offers the contradictory view that it causes the native members to feel more threatened, resulting in more, not less, hostility toward and prejudice against ethnic minorities.

Empirical findings indicate that greater interaction can indeed reduce outgroup prejudice and hostility, such as fears that immigrants pose a threat (at least among leftist voters) (Homola and Tavits 2018).). The lack of consensus on when and why ethnic/racial heterogeneity may dampen associational life (e.g., generalized trust and civic participation) has been attributed to several problems. Notably, they include the absence of clear definitions and measurements and the inconsistent levels at which the diversity-cohesion linkage has been tested (for review, see Van Der Meer and Tolsma 2014). Aside from methodological limitations, the current literature suffers from an empirical bias: findings almost exclusively derive from data on the US, Canada and Europe (Mavridis 2015). ${ }^{1}$ As a result, we know relatively little about whether and how the issue under consideration applies to other (less developed) regions of the world, despite the fact that immigration is no longer a South-to-North but a universal phenomenon.

The focus of this study is Georgia, an integral part of the South Caucasus referred to as the new world disorder' (Cornell 2005) for its ongoing ethno-political disputes and territorial warfare. The unresolved situation with the two separatist regions, Abkhazia and South Ossetia, exemplifies the country's continuing struggle (De Waal 2010). According to the latest government report (State Commission on State Commission on Migration Issues 2018), immigration to Georgia has been on the rise from neighboring states, namely Russia, Turkey, Armenia, Azerbaijan, and Ukraine. Since 2015, the number of residence permits issued to foreigners has tripled. Georgia's history of ethnic conflicts and contemporary demographic trends provide a unique opportunity to analyze the unsettled question of immigration and its reputedly negative effects in a non-western context. In addition to bridging an empirical gap, this study offers conceptual contributions. Previous research has largely emphasized the consequences of diversity indices (e.g., ethnic fractionalization) on measures of cohesion at the individual level (Schaeffer 2013). A limitation of this approach is that it does not explicitly take into account outgroup contact, which is critical for understanding diversity-cohesion dynamics (Hewstone 2015).

To the extent that the contact variable is considered, it is often treated as a mediator/moderator (Savelkoul et al. 2011). Relatedly, other researchers have probed whether interaction with foreigners magnifies or reduces feelings of ethnic threat (Schlueter and Scheepers 2010). Relatively rare in the literature are studies that directly investigate contact and attitude as primary predictors of social cohesion. These two concepts are related yet distinct. Contact refers to actual intergroup experiences. Attitude does not. One may feel neutral or even favorable toward an ethnic minority group. Such subjective orientation, however, does not necessarily imply interacting with its members. Conversely, one may be actively engaged in intergroup contact. But that is not synonymous with having a positive outgroup attitude, since it is possible that contact stems from necessity, not choice. Therefore, how a person feels about an immigrant and whether the individual has contact with an immigrant are separate issues. Given this dichotomy, incorporating both measures into data analysis would offer a fuller understanding.

Social cohesion is related to two aspects or dimensions of ethnic diversity: objective and subjective (Van Der Meer and Tolsma 2014). The objective aspect has to do with the sheer size of immigrants or foreigners. The subjective side concerns how natives feel about them. Concerning the latter, perceived threat by the existence of a foreign group, for example, can be measured by using survey items that ask respondents about their attitudes toward its members. And by aggregating this measure at the regional level, we can examine how the broader context can affect individual-level social cohesion variables

1 According to one of the most highly cited and recent systematic reviews, "research has been most prolific on the United States (18 studies), the United Kingdom (11), the Netherlands (10), and Canada (7)" (Van Der Meer and Tolsma 2014, p. 466). 
such as organizational participation and trust. The present study shifts the analytic angle to these very issues: the extent to which outgroup interaction and anti-immigrant orientation are associated with generalized trust and civic engagement for a nationally representative sample of Georgian adults. Specifically, this paper is guided by the following questions: How, if at all, are contact with, and attitude toward, foreigners independently related to social cohesion at individual and regional levels? And how are these two variables interactively related to social cohesion across the two levels of analysis?

\section{Methods}

\subsection{Sample}

Data are drawn from the Caucasus Barometer, an annual survey conducted by the CRRC (Caucasus Research Resource Center), which was founded in 2003 by Eurasia Partnership Foundation (EPF) with financial support from the Carnegie Foundation of New York. The present study focuses on the Caucasus Barometer 2017 Georgia. Caucasus Research Resource Center (CRRC) Georgia, the latest version, which contains a wealth of demographic, social, economic and political variables pertaining to a probability sample of adults $(\mathrm{N}=2379)$. Computer-assisted personal interview (CAPI) method was used to collect data using a multi-stage cluster sampling design. More details on survey implementations and other documents are available at the online data repository maintained by the CRRC (www.caucausbarometer.org/en/downloads). Summary statistics for the variables are provided in Table 1.

Table 1. Summary of Descriptive Statistics.

\begin{tabular}{|c|c|c|c|c|}
\hline & Mean/Proportion & S.D. & Min. & Max. \\
\hline \multicolumn{5}{|l|}{ Outcome measure } \\
\hline Generalized trust & 4.10 & 2.58 & 1.00 & 10.00 \\
\hline Civic engagement & 1.23 & 1.15 & 0.00 & 4.00 \\
\hline \multicolumn{5}{|c|}{ (Individual-level variables; $\mathrm{N}=2379$ ) } \\
\hline Anti_Imm & 2.92 & 0.84 & 1.00 & 5.00 \\
\hline Contact & 0.26 & - & 0.00 & 1.00 \\
\hline Age & 51.97 & 18.52 & 18.00 & 102.00 \\
\hline Health & 2.97 & 0.94 & 1.00 & 5.00 \\
\hline Income & 4.09 & 1.16 & 1.00 & 8.00 \\
\hline Education & 5.02 & 1.47 & 1.00 & 8.00 \\
\hline Georgian & 0.84 & - & 0.00 & 1.00 \\
\hline Male & 0.36 & - & 0.00 & 1.00 \\
\hline Religiosity & 2.99 & 1.39 & 1.00 & 7.00 \\
\hline Married & 0.57 & - & 0.00 & 1.00 \\
\hline$S W B$ & 7.12 & 2.35 & 1.00 & 10.00 \\
\hline \multicolumn{5}{|c|}{ (Regional-level variables; N = 194) } \\
\hline Northeast_R & 0.12 & - & 0.00 & 1.00 \\
\hline Northwest_R & 0.13 & - & 0.00 & 1.00 \\
\hline Southeas_R & 0.09 & - & 0.00 & 1.00 \\
\hline Southwest_R & 0.07 & - & 0.00 & 1.00 \\
\hline Northeast_U & 0.04 & - & 0.00 & 1.00 \\
\hline Norhwest_U & 0.10 & - & 0.00 & 1.00 \\
\hline Southeast_U & 0.05 & - & 0.00 & 1.00 \\
\hline Southwest_U & 0.05 & - & 0.00 & 1.00 \\
\hline Anti_Imm & 2.92 & 0.42 & 1.00 & 4.17 \\
\hline Contact & 0.26 & - & 0.00 & 1.00 \\
\hline
\end{tabular}

Source: Caucasus Barometer 2017 Georgia. Caucasus Research Resource Center (CRRC).

\subsection{Dependent Measures}

There are two social cohesion variables: Generalized Trust, one of the most frequently used (Dinesen and Sonderskov 2018), and Civic Engagement. The former, an attitudinal measure, is based on the following question coded on a 10-point scale: "Generally speaking, would you say that most 
people in/country/can be trusted, or that you can't be too careful in dealing with people?" (10 = "Most people can be trusted"). The latter, a behavioral measure, is operationalized according to the level of participation during the last six months in civic activities such as: "Helped clean public space; "Did volunteer work without expecting compensation"; "Attended a public meeting"; and "Donated money to a nonreligious charity." Answers (coded 1 if "Yes") were merged to create an index ranging from 0 to 4 .

\subsection{Main Predictors}

Two independent variables gauge people's attitudes toward foreigners and levels of interaction with them. Anti_Immgr is derived from the survey item that asks: "How would you characterize your attitude toward the foreigners who come to Georgia and stay for more than 3 months?" $(1=$ very bad, 5 = very good). Responses are reverse-coded, i.e., a higher score equals a greater anti-immigrant attitude. Contact is measured based on the frequency of outgroup interaction: "Have you had any form of contact with foreigners who have stayed in Georgia for more than 3 months? Answers are dichotomized such that having at least some contact ( $29 \%$ of the sample) is coded 1 . In models not shown, intergroup contact was alternatively measured using its original 3-point scale. Main findings were consistent with the ones presented below.

\subsection{Control Variables}

A host of confounders are adjusted for, including: age, self-rated health $(1=$ "very poor," $5=$ "very good"), household income coded on an 8-point scale, education ( 1 = "no education," $8=$ "post-secondary education"), ethnicity (Georgian $=1)$, gender (male $=1)$, marital status (married $=1)$, subjective wellbeing $(S W B)$ measured using a scale ranging from 1 ("very unhappy") to 10 ("very happy"), and religiosity, self-evaluation of the importance of religion ( 1 = "not very important," 7 = "very important"). In addition, at the contextual level, a set of dummy variables control for regional fixed effects- Northeast Rural, Southwest Rural, Northwest Urban, Southeast Urban, etc. (reference group: Tbilisi). Also included are aggregate versions of the two main predictor variables, L2 Anti_Immgr and L2 Contact, by averaging individual responses across 194 primary sampling units (regional clusters). ${ }^{2}$

\subsection{Analytic Strategy}

To examine contextual and cross-level interaction (moderation) effects, mixed-effects models are estimated. The two outcome variables call for different modeling approaches. Generalized Trust is treated as an interval variable in running multilevel linear regression models. ${ }^{3}$ Civic Engagement, in contrast, is a count variable and thus Poisson regression models are run. ${ }^{4}$ Individual cases are weighted using the variable provided in the dataset. Statistical analyses are performed using HLM 7.03 (Raudenbush et al. 2011).

2 Caucasus Barometer 2017 Georgia. Caucasus Research Resource Center (CRRC) provides unique numerical identifiers for these regional clusters, which are used to aggregate individual responses. However, no specific details are given concerning the population sizes or locations of these regions. As is the case with most surveys, the information is not released in order to protect the identities of the survey respondents.

3 Multilevel modeling is necessary when data are clustered, which violates the independence assumption critical for conventional (Ordinary Least Squares) regression analysis. Multilevel models explicitly acknowledge the clustered data structure and allow for residual components at each level in the hierarchy. In Caucasus Barometer 2017 Georgia. Caucasus Research Resource Center (CRRC), individual respondents are nested across 194 regional clusters, i.e., individuals in the same region are more similar with one another than those located in another region. Multilevel analysis addresses this problem of correlated errors by partitioning the residual variance into a between-region component (the variance of the region-level residuals) and a within-region component (the variance of the individual-level residuals).

4 Poisson regression coefficients are interpreted as the difference between the log of expected counts. Formally, this is expressed as: $\beta=\log (\mu x+1)-\log (\mu x)$, where $\beta$ is the regression coefficient, $\mu$ is the expected count and the subscripts represent where the predictor variable, say $x$, is evaluated at $x$ and $x+1$ (implying a one unit change in the predictor variable $x)$. Since the difference of two logs is equal to the $\log$ of their quotient, $\log (\mu x+1)-\log (\mu x)=\log (\mu x+1 / \mu x)$, we can also interpret the parameter estimate as the log of the ratio of expected counts. 


\section{Results}

For both outcome measures, a null or unconditional model without any covariates is initially estimated to check for the degree of clustering (data dependence). According to results from Model 1 in Tables 2 and 3, the intraclass correlation (ICC) is $15.6 \%$ and $4.8 \%$, respectively. ${ }^{5}$ For Generalized Trust, according to Model 2 in Table 2, having at least some contact with foreigners is a positive predictor $(p<0.05)$. Model 3 shows that the reverse is true for holding a negative attitude toward them $(p<0.01)$. When both predictors are included simultaneously, we find that only Anti_Immgr remains significant $(p<0.01)$, i.e., the effect of Contact is fully mediated. Moving onto Civic Engagement, we turn to the Poisson estimates summarized in Table 3. Interestingly, results are the opposite of what we saw in Table 2. Being unfavorably disposed to foreigners is no longer related to this (behavioral) social cohesion measure. Interaction with foreigners, by contrast, emerges as a significant predictor $(p<0.001)$, as illustrated in the full model (Model 4). Effect size is expressed as a percent change in the estimated count. The incident rate ratio (IRR) indicates that those who interact with foreigners have a rate that is 1.465 times $(46.5 \%)$ higher for participating in public life.

Table 2. Multilevel Linear Regression Analysis (Caucasus Barometer 2017 Georgia. Caucasus Research Resource Center CRRC).

\begin{tabular}{ccccccccc}
\hline DV: Generalized Trust & \multicolumn{2}{c}{ Model 1 } & \multicolumn{2}{c}{ Model 2 } & \multicolumn{2}{c}{ Model 3 } & \multicolumn{2}{c}{ Model 4 } \\
\hline & Coef & $(\mathrm{SE})$ & Coef & $(\mathrm{SE})$ & Coef & $(\mathrm{SE})$ & Coef & $(\mathrm{SE})$ \\
Constant & $4.186^{* * *}$ & $(0.104)$ & $4.178^{* * *}$ & $(0.105)$ & $4.187^{* * *}$ & $(0.105)$ & $4.181^{* * *}$ & $(0.105)$ \\
Contact & & & $0.324^{*}$ & $(0.154)$ & & & 0.232 & $(0.155)$ \\
Anti_Immgr & & & & & $-0.267^{* *}$ & $(0.086)$ & $-0.243^{* *}$ & $(0.087)$ \\
L2 variance $(\tau)$ & $1.029 * * *$ & \multicolumn{2}{c}{$1.033^{* * *}$} & \multicolumn{2}{c}{$1.042^{* * *}$} & $1.037^{* * *}$ \\
L1 variance $\left(\sigma^{2}\right)$ & 5.581 & \multicolumn{2}{c}{5.592} & \multicolumn{2}{c}{5.563} & 5.571 \\
Deviance & $11,032.64$ & \multicolumn{2}{c}{$10,822.97$} & & $10,627.73$ & $10,473.48$ \\
\hline
\end{tabular}

Note: Standard errors in parentheses. $\mathrm{N}=2246$ respondents clustered in 194 regional units. $p^{*}<0.05, p^{* *}<0.01$, $p^{* * *}<0.001$ (two-tailed tests).

Tables 4 and 5 introduce the background variables (Age, Health, Income, Education, Ethnicity, Male, Religiosity, Married, and SWB) and contextual-level covariates. Model 1 in Table 4 presents evidence that, amongst individual-level controls, being unfavorably oriented toward foreigners is negatively related to trusting others $(p<0.01)$. This finding remains consistent even after adding regional average measures of Anti_Immgr and Contact (Model 2) as well as regional dummies (Model 3). To examine how the two main predictors are further related to Civic Engagement, we proceed with the results in Table 5. As was the case with the bivariate models, only Contact emerges as a significant factor. The linkage between outgroup interaction and involvement in civic life remains robust across the first three models under different specifications ( $p<0.001)$. Lastly, the fourth model (Model 4 ) reveals that this association is not constant but varies according to the overall attitude toward foreigners at the regional level. As indicated by the negative cross-level interaction term $(p<0.01)$, it is weaker in more anti-immigrant communities. Figure 1 illustrates this contingent relationship, while holding all other variables at their numerical means. Among those who had at least some contact with outgroup members, the average predicted value for civic engagement is greater (1.7 vs. 1.3) if they lived in a lower-quartile region that was "less" antagonistic to foreigners than in a "more" hostile one, i.e., an upper-quartile region.

5 Calculating ICCs is an important step to check whether running multilevel model is warranted in the first place. It is similar to running one-way ANOVA, results of which show that trust and civic engagement vary significantly across the higher level unit (regions). At the regional level, the two outcome variables are aggregated and rescaled or standardized into $z$-scores with the mean of zero and the standard deviation of one. For trust, $51.5 \%$ (100) regions have measures above zero; for civic engagement, the figure is $51 \%(99)$. 
Table 3. Multilevel Poisson Regression Analysis (Caucasus Barometer 2017 Georgia. Caucasus Research Resource Center CRRC).

\begin{tabular}{|c|c|c|c|c|c|c|c|c|c|c|c|c|}
\hline DV: Civic Engagement & & Model 1 & & & Model 2 & & & Model 3 & & & Model 4 & \\
\hline & Coef & (SE) & IRR & Coef & (SE) & IRR & Coef & (SE) & IRR & Coef & (SE) & IRR \\
\hline Constant & 0.312 & $(0.043)$ & $1.366^{* * *}$ & 0.312 & $(0.044)$ & $1.366^{* * *}$ & 0.293 & $(0.044)$ & $1.340 * * *$ & 0.294 & $(0.044)$ & $1.342 * * *$ \\
\hline Anti_Immgr & & & & -0.041 & $(0.027)$ & 0.960 & & & & -0.003 & $(0.027)$ & 0.997 \\
\hline Contact & & & & & & & 0.379 & $(0.046)$ & $1.461^{* * *}$ & 0.382 & $(0.047)$ & $1.465^{* * *}$ \\
\hline L2 variance $(\tau)$ & & $0.167^{* * *}$ & & & $0.167^{* * *}$ & & & $0.162 * * *$ & & & $0.163^{* * *}$ & \\
\hline Reliability estimate & & 0.727 & & & 0.719 & & & 0.718 & & & 0.711 & \\
\hline Log likelihood & & -3544.88 & & & -3415.62 & & & -3134.18 & & & -3033.69 & \\
\hline
\end{tabular}

Note: Standard errors in parentheses. IRR = Incidence Rate Ratio. N = 2203 respondents clustered in 194 regional units. $p^{*}<0.05, p^{* *}<0.01, p^{* * *}<0.001$ (two-tailed tests).

Table 4. Multilevel Linear Regression Estimates from Predicting Generalized Trust

\begin{tabular}{|c|c|c|c|c|c|c|}
\hline & \multicolumn{2}{|c|}{ Model 1} & \multicolumn{2}{|c|}{ Model 2} & \multicolumn{2}{|c|}{ Model 3} \\
\hline & Coef. & $(\mathrm{SE})$ & Coef. & (SE) & Coef. & $(\mathrm{SE})$ \\
\hline Constant & $4.68^{* * *}$ & $(0.31)$ & $4.639^{* * *}$ & $(0.333)$ & $4.894^{* * *}$ & $(0.398)$ \\
\hline \multicolumn{7}{|l|}{ (Individual-level) } \\
\hline Contact & 0.231 & $(0.18)$ & 0.228 & $(0.18)$ & 0.225 & $(0.18)$ \\
\hline \multicolumn{7}{|l|}{ Anti_Immgr (Contextual-level) } \\
\hline L2 Contact & $-0.269^{* *}$ & $(0.088)$ & 0.472 & $(0.443)$ & 0.281 & $(0.471)$ \\
\hline L2 Anti_Immgr & & & -0.01 & $(0.259)$ & -0.128 & $(0.263)$ \\
\hline Regional dummies & \multicolumn{2}{|c|}{ No } & \multicolumn{2}{|c|}{ No } & \multicolumn{2}{|c|}{ Yes } \\
\hline L2 variance $(\tau)$ & \multicolumn{2}{|c|}{$0.927^{* * *}$} & \multicolumn{2}{|c|}{$0.921^{* * *}$} & \multicolumn{2}{|c|}{$0.877^{* * *}$} \\
\hline $\mathrm{L} 1$ variance $\left(\sigma^{2}\right)$ & \multicolumn{2}{|c|}{5.503} & \multicolumn{2}{|c|}{5.5} & \multicolumn{2}{|c|}{5.49} \\
\hline Deviance & \multicolumn{2}{|c|}{9172.52} & \multicolumn{2}{|c|}{9170.98} & \multicolumn{2}{|c|}{9163.67} \\
\hline
\end{tabular}

Data source: Caucasus Barometer 2017 Georgia. Caucasus Research Resource Center (CRRC); L-1 N = 1973, L-1 N = 192. Note: Standard errors in parentheses. Models control for Age, Health, Income, Education, Ethnicity, Male, Religiosity, Married, and SWB. 8 regional dummies include e.g., Northeast Urban, Northwest Rural, Southeast Rural, and Southwest Urban (Ref.: Tbilisi). $p^{*}<0.05, p^{* *}<0.01, p^{* * *}<0.001$ (two-tailed tests). 
Table 5. Multilevel Poisson Regression Estimates from Predicting Civic Engagement.

\begin{tabular}{|c|c|c|c|c|c|c|c|c|c|c|c|c|}
\hline & \multicolumn{3}{|c|}{ Model 1} & \multicolumn{3}{|c|}{ Model 2} & \multicolumn{3}{|c|}{ Model 3} & \multicolumn{3}{|c|}{ Model 4} \\
\hline & Coef. & (SE) & IRR & Coef. & (SE) & IRR & Coef. & (SE) & IRR & Coef. & (SE) & IRR \\
\hline $\begin{array}{c}\text { Constant } \\
\text { (Individual-level) }\end{array}$ & 0.144 & $(0.119)$ & 1.155 & 0.090 & $(0.108)$ & 1.094 & 0.343 & $(0.122)$ & $1.41^{* *}$ & 0.323 & $(0.124)$ & $1.381 *$ \\
\hline Anti_Immgr & 0.014 & $(0.03)$ & 1.014 & 0.012 & $(0.03)$ & 1.012 & 0.012 & $(0.03)$ & 1.012 & 0.013 & $(0.029)$ & 1.013 \\
\hline $\begin{array}{c}\text { Contact } \\
\text { (Contextual-level) }\end{array}$ & 0.231 & $(0.051)$ & $1.26^{* * *}$ & 0.227 & $(0.051)$ & $1.255^{* * *}$ & 0.222 & $(0.051)$ & $1.249^{* * *}$ & 0.204 & $(0.051)$ & $1.231^{* * *}$ \\
\hline L2 Anti_Immgr & & & & -0.230 & $(0.143)$ & 0.794 & -0.269 & $(0.134)$ & 0.764 * & -0.255 & $(0.138)$ & 0.774 \\
\hline $\begin{array}{l}\text { L2 Contact } \\
\text { (Cross-level) }\end{array}$ & & & & 0.102 & $(0.259)$ & 1.108 & -0.041 & $(0.24)$ & 0.959 & -0.042 & $(0.242)$ & 0.959 \\
\hline $\begin{array}{c}\text { Contact } \mathrm{x} \\
\text { L2 Anti_Immgr }\end{array}$ & & & & & & & & & & -0.319 & $(0.122)$ & $0.727^{* *}$ \\
\hline Regional dummies & & No & & & No & & & Yes & & & Yes & \\
\hline L2 variance $(\tau)$ & & $0.148^{* * *}$ & & & $0.138^{* * *}$ & & & $0.105^{* * *}$ & & & $0.106^{* * *}$ & \\
\hline Reliability estimate & & 0.666 & & & 0.652 & & & 0.596 & & & 0.598 & \\
\hline Log likelihood & & -2855.07 & & & -2851.17 & & & -2836.16 & & & -2832.88 & \\
\hline
\end{tabular}

Data source: Caucasus Barometer 2017 Georgia. Caucasus Research Resource Center (CRRC); L-1 N = 1934, L-2 N = 192. Note: IRR = Incidence Rate Ratio. Standard errors in parentheses. Models control for Age, Health, Income, Education, Ethnicity, Male, Religiosity, Married, and SWB. 8 regional dummies include, e.g., Northeast Urban, Northwest Rural, Southeast Rural, and Southwest Urban (Ref.: Tbilisi). $p^{*}<0.05, p^{* *}<0.01, p^{* * *}<0.001$ (two-tailed tests). 


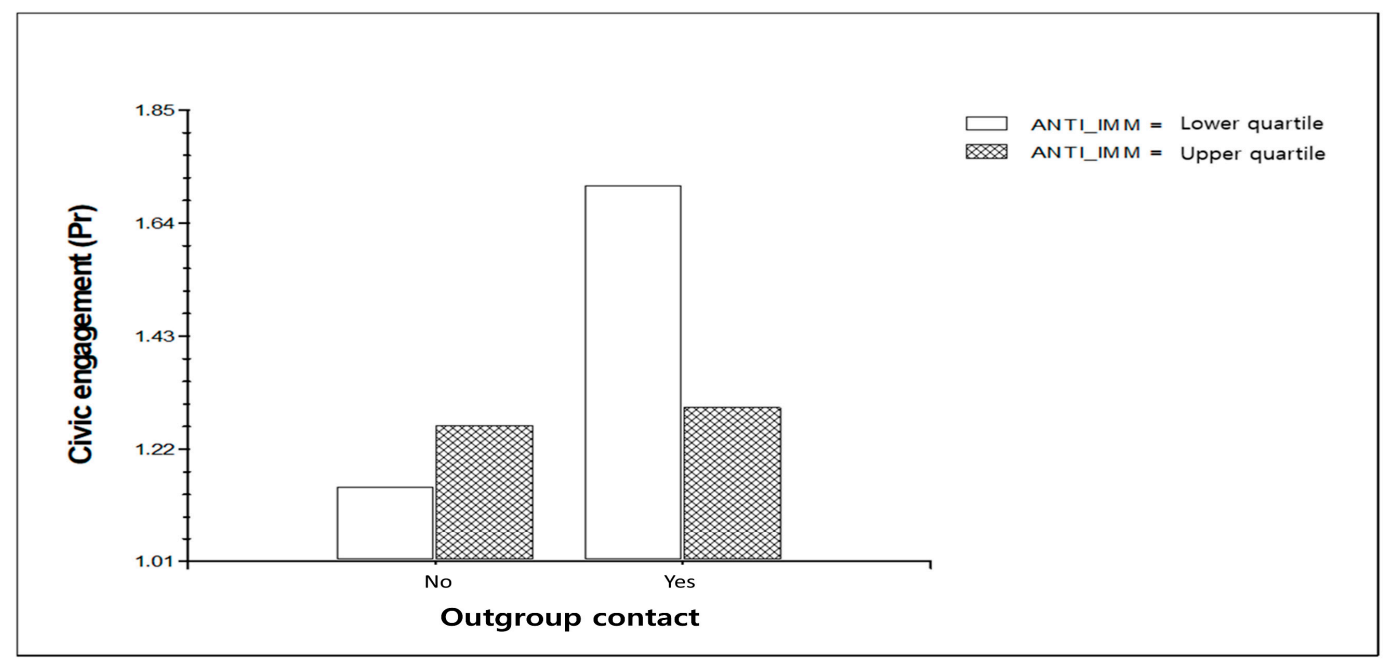

Figure 1. Predicted civic engagement as a function of intergroup contact and regional of level anti-immigrant attitude (at lower and upper quartiles).

\section{Conclusions}

Whether diversity leads to less cohesive society has been a highly contentious issue. Since Putnam (2007) controversial piece based on the US case, many studies have sought to test his so-called "constrict" argument in other (largely European) settings. Suffice it to say that the accumulated evidence is inconsistent, if not contradictory. The present study adds to the scholarship by offering novel findings based on a representative sample from the South Caucasus. Prior studies have largely measured ethnic diversity at higher-level units (neighborhoods, communities, and countries) and how this composition is associated with individual measures of social cohesion such as trusting others and participating in public life. In this line of research, interethnic contact and outgroup attitude are considered primarily as a mediator or moderator. In a related vein, scholars have also examined how intergroup contact reduces feelings of ethnic threat. As a result, there is limited discussion on the main effects of contact with, and attitude toward, immigrants as experienced by native members of society. This study thus focused on, first, (1) how interaction with immigrants is related to generalized trust and civic engagement at individual and contextual (regional) levels, second, (2) how negative attitude toward foreigners is related to generalized trust and civic engagement at individual and contextual (regional) levels, and, finally, (3) how intergroup contact and outgroup attitude are interactively related to the two measures of social cohesion across these distinct levels of analysis.

Findings from the multilevel models suggest, first and foremost, that social cohesion is a "multidimensional concept" (Ariely 2014). Depending on the method of operationalization, its relationship to outgroup contact and attitude toward foreigners varies significantly. Specifically, an attitudinal measure (Generalized Trust) was related to a subjective predictor (Anti_Immgr), whereas a behavioral measure (Civic Engagement) was related to an objective predictor (Contact), a finding that complements an early study about the importance of conceptual dichotomies in measurement (Anderson and Paskeviciute 2006). Clearly, social cohesion is "multifaceted" (Laurence 2011). It encompasses a variety of concepts and related measures, which could vary across empirical contexts, i.e., different cultural, national and institutional settings. In this study, trust and civic participation were used as the outcome variables. Future research should incorporate alternative ways of operationalizing social cohesion for richer analysis. At the same time, social cohesion must be better conceptualized, so that researchers can more effectively replicate findings based on a common definition.

Research has systematically demonstrated that contact can reduce outgroup bias (for review, see Pettigrew and Tropp 2006; Dovidio et al. 2017). As has been pointed out, however, intergroup contact is often not directly measured in statistical modeling (Hewstone 2015). Rather, it is assumed to take 
place in the context of ethnic diversity. That is, the bulk of existing research analyzes the relationship between the size of immigrant stock measured at a contextual level (e.g., community, neighborhood, country) and social cohesion measured at the individual level. In doing so, a critical and problematic assumption is made: that the presence of foreign population creates intergroup contact. This has been a major limitation in the literature, one that has been widely recognized (Laurence and Bentley 2018). The present study addresses this thorny issue by explicitly examining its direct effect on social cohesion. In addition, it offers a more nuanced analysis by incorporating an additional measure: anti-immigrant attitude. As the results illustrate, contact and attitude are complexly related and have distinct effects on the two measures of social cohesion. Intergroup contact increases civic participation, while anti-immigrant attitude diminishes trust in others. Moreover, the bivariate relationship between contact and trust is fully mediated by negative attitude toward immigrants. Further still, the attitude variable moderates the association between contact and native members' engagement in civic activities.

According to findings of this study, one significant and positive consequence of intergroup contact is that it leads to more civic involvement. It is also important to recognize that the level of analysis matters (Lancee 2017). The beneficial impact of contact is found to be lower in communities with higher anti-immigrant sentiments. One policy suggestion is to increase intergroup contact. Studies have shown that residential segregation is a critical factor that can impede interaction across ethnic and racial groups (Laurence 2011; Schaeffer 2013). To facilitate contact across ethno-racial boundaries, therefore, it is critical to better integrate people of different origins. Government-sponsored cultural exchange programs could produce beneficial results. Removing barriers for ethnic minorities to move into neighborhoods predominantly occupied by native populations also seems urgent. Empirical findings indicate that greater interaction can indeed reduce outgroup prejudice and hostility, such as feelings of fear and threat toward immigrants (Homola and Tavits 2018). Needless to say, finding ways to encourage and sustain more frequent intergroup interaction is a top priority for all concerned parties. In Georgia, a country that has traditionally been fraught with interethnic tensions and conflicts, having a negative attitude toward foreigners not only lowers generalized trust (at the individual level) but also weakens the strength of association between contact and civic engagement (at the regional level). This case study has broader implications, both theoretically and empirically. As a recent meta-analysis makes clear, however, whether contact or conflict hypothesis better explains the association between diversity and cohesion remains moot (Kaufmann and Goodwin 2018). More comparative studies are in order to shed further light on this critically urgent matter, one that constitutes the core of current debate on pros and cons of immigration.

Author Contributions: H.H.-s.K. conceived of the project, analyzed the data, and drafted the paper.

Funding: This research received no external funding.

Acknowledgments: I thank the Caucasus Research Resource Center (CRRC) for making the data publicly available.

Conflicts of Interest: The author declares no conflict of interest.

\section{References}

Anderson, Christopher J., and Aida Paskeviciute. 2006. How Ethnic and Linguistic Heterogeneity Influence the Prospects for Civil Society: A Comparative Study of Citizenship Behavior. The Journal of Politics 68: 783-802. [CrossRef]

Ariely, Gal. 2014. Does Diversity Erode Social Cohesion? Conceptual and Methodological Issues. Political Studies 62: 573-95. [CrossRef]

Castells, Stephen, Hein de Haas, and Mark. J. Miller. 2014. Age of Migration. New York: Guilford Press.

Caucasus Barometer 2017 Georgia. Caucasus Research Resource Center (CRRC). Project Coordinator: Dr. Tinatin Zurabishvili, CRRC-Georgia. Available online: https://caucasusbarometer.org/en/cb2017ge/factsheet/ (accessed on 14 January 2019).

Cornell, Svante. 2005. Small Nations and Great Powers: A Study of Ethnopolitical Conflict in the Caucasus. London and New York: Routledge. First published 2001. 
De Waal, Thomas. 2010. The Caucasus: An Introduction. New York: Oxford University Press.

Dinesen, Peter Thisted, and Kim Mannemar Sonderskov. 2018. Ethnic Diversity and Social Trust. A Critical Review of the Literature and Suggestions for a Research Agenda. In The Oxford Handbook on Social and Political Trust. Oxford: Oxford University Press.

Dovidio, John F., Angelika Love, Fabian M. H. Schellhaas, and Miles Hewstone. 2017. Reducing Intergroup Bias through Intergroup Contact: Twenty Years of Progress and Future Research. Group Processes and Intergroup Relations 20: 606-20. [CrossRef]

Fieldhouse, Edward, and David Cutts. 2010. Does Diversity Damage Social Capital? A Comparative Study of Neighbourhood Diversity and Social Capital in the US and Britain. Canadian Journal of Political Science 43: 289-318. [CrossRef]

Helbling, Marc, Tim Reeskens, and Dietlind Stolle. 2015. Political Mobilisation, Ethnic Diversity and Social Cohesion: The Conditional Effect of Political Parties. Political Studies 63: 101-22. [CrossRef]

Hewstone, Miles. 2015. Consequences of Diversity for Social Cohesion and Prejudice: The Missing Dimension of Intergroup Contact. Journal of Social Issues 71: 417-38. [CrossRef]

Homola, Jonathan, and Margit Tavits. 2018. Contact Reduces Immigration-Related Fears for Leftist but not for Rightist Voters. Comparative Political Studies 51: 1789-820. [CrossRef]

Kaufmann, Eric, and Matthew J. Goodwin. 2018. The Diversity Wave: A Meta-Analysis of the Native-Born White Response to Ethnic Diversity. Social Science Research 76: 120-31. [CrossRef] [PubMed]

Lancee, Bram. 2017. Diversity, Trust and Social Cohesion. In Trust at Risk: Implications for EU Policies and Institutions. Brussels: European Commission, Directorate-General for Research and Coordination, pp. 167-75.

Laurence, James. 2011. The Effect of Ethnic Diversity and Community Disadvantage on Social Cohesion. European Sociological Review 27: 70-89. [CrossRef]

Laurence, James, and Lee Bentley. 2018. Countervailing Contact: Community Ethnic Diversity, Anti-Immigrant Attitudes and Mediating Pathways of Positive and Negative Inter-Ethnic Contact in European Societies. Social Science Research 69: 83-110. [CrossRef] [PubMed]

Mavridis, Dimitris. 2015. Ethnic Diversity and Social Capital in Indonesia. World Development 67: $376-95$. [CrossRef]

Pettigrew, Thomas F., and Linda R. Tropp. 2006. A Meta-Analytical Test of the Intergroup Contact Theory. Journal of Personality and Social Psychology 90: 751-83. [CrossRef] [PubMed]

Putnam, Robert D. 2007. E Pluribus Unum: Diversity and Community in the Twenty-First Century. The 2006 Johan Skytte Prize Lecture. Scandinavian Political Studies 30: 137-74. [CrossRef]

Raudenbush, Steve, Anthony Bryk, and Richard Congdon. 2011. HLM 7.03 for Windows. [Computer software]. Skokie, IL: Scientific Software International, Inc.

Savelkoul, Michael, Maurice Gesthuizen, and Peer Scheepers. 2011. Explaining Relationships Between Ethnic Diversity and Informal Social Capital Across European Countries and Regions: Tests of Constrict, Conflict, and Contact Theory. Social Science Research 40: 1091-107. [CrossRef]

Schaeffer, Merlin. 2013. Can Competing Diversity Indices Inform Us about Why Ethnic Diversity Erodes Social Cohesion? A Test of Five Diversity Indices in Germany. Social Science Research 42: 755-74. [CrossRef] [PubMed]

Schlueter, Elmar, and Peer Scheepers. 2010. The Relationship Between Outgroup Size and Anti-Outgroup Attitudes: A Theoretical Synthesis and Empirical Test of Group Threat- and Intergroup Contact Theory. Social Science Research 39: 285-95. [CrossRef]

State Commission on Migration Issues. 2018. Migration Profile of Georgia 2017. Available online: http: //migration.commission.ge/files/migration_profile_2017_eng_final_pdf (accessed on 14 January 2019).

Van Der Meer, Tom, and Jochem Tolsma. 2014. Ethnic Diversity and Its Effects on Social Cohesion. Annual Review of Sociology 40: 459-78. [CrossRef]

Ziller, Conrad, Matthew Wright, and Miles Hewstone. 2018. Immigration, Social Trust, and Moderating Role of Value Contexts. Social Sciences Research. [CrossRef]

(C) 2019 by the author. Licensee MDPI, Basel, Switzerland. This article is an open access article distributed under the terms and conditions of the Creative Commons Attribution (CC BY) license (http://creativecommons.org/licenses/by/4.0/). 